\title{
АРХЕОЛОГИЯ
}

DOI: https://doi.org/10.15688/jvolsu4.2017.2.1

UDC 94(5):902/904

Submitted: 10.02 .2017

LBC 63.3(54)+63.48(5)

Accepted: 04.04.2017

\section{SOME FEATURES OF THE FUNCTIONING OF THE NORTHERN BRANCH OF THE GREAT SILK ROAD ${ }^{1}$}

\author{
Anatoliy S. Skripkin \\ Volgograd State University, Volgograd, Russian Federation
}

\begin{abstract}
The fact of existing economic relations in the north branch of The Great silk route is usually restored according to Claudius Ptolemey. There are some evidences to connect their activation with the establishment of political domination of Alans in the South-East of Europe. The analysis of archaeological material gives the information that not all findings of Chinese artifacts in Sarmatian burial complexes of the first century AD are the result of trade links and most of them have been brought here in the result of nomads' migrations.

The appearance of the Alans in the steppes of South-Eastern Europe refers to the first century AD. This tribal association was formed in Central Asia. Alans subdue the vast steppes from the Aral sea to the Don. In the early historical stage the Lower Don becomes their political center. In burials belonging to the Alanian nobility, a large number of items of Eastern origin were discovered. A great number of them were brought here upon the arrival of the new nomads. Economic relations in this area begin to improve after the establishment of political stability, which was reflected in the composition of Claudius Ptolemy.

Key words: Great silk route, trade links, things of Chinese origin, Alans, Xiongnu.

Citation. Skripkin A.S. Some Features of the Functioning of the Northern Branch of the Great Silk Road. Vestnik Volgogradskogo gosudarstvennogo universiteta. Serija 4, Istorija. Regionovedenie. Mezhdunarodnye otnoshenija [Science Journal of Volgograd State University. History. Area Studies. International Relations], 2017, vol. 22, no. 2, pp. 6-14. (in Russian).
\end{abstract}

\section{О НЕКОТОРЫХ ОСОБЕННОСТЯХ НАЧАЛА ФУНКЦИОНИРОВАНИЯ СЕВЕРНОГО ОТВЕТВЛЕНИЯ ВЕЛИКОГО ШЕЛКОВОГО ПУТИ ${ }^{1}$}

\section{Анатолий Степанович Скрипкин}

Аннотация. Наличие экономических связей по северному ответвлению Великого шелкового пути обычно реконструируется по сведениям Клавдия Птолемея. Есть основания связывать их активизацию с установлением политического господства аланов на юго-востоке Европы. Анализ археологического материала свидетельствует, что не все находки вещей, связанные с Китаем, в сарматских погребальных комплексах первых веков нашей эры являются результатом торговых операций, многие из них были принесены сюда в результате миграции кочевников. 
Появление аланов в степях Юго-Восточной Европы относится к I в. нашей эры. Это племенное объединение сформировалось в Средней Азии. Аланы подчиняют обширные степные пространства от Аральского моря до Дона. На раннем этапе истории их политическим центром становится Нижний Дон. В погребениях, принадлежащих аланской знати, обнаружено большое количество предметов восточного происхождения, которые попали сюда в большинстве своем вместе с приходом новых кочевников. Экономические отношения в этом районе начинают налаживаться после установления политической стабильности, что нашло отражение в сочинении Клавдия Птолемея.

Ключевые слова: Великий шелковый путь, торговые связи, вещи китайского происхождения, аланы, хунну.

Цитирование. Скрипкин, А. С. О некоторых особенностях начала функционирования северного ответвления Великого шелкового пути / А. С. Скрипкин // Вестник Волгоградского государственного университета. Серия 4, История. Регионоведение. Международные отношения. - 2017. - Т. 22, № 2. - С. 6-14.

Тема, связанная с историей Великого шелкового пути, постоянно находится в поле зрения исследователей. Сам термин был введен в научный оборот немецким геологом и путешественником Ф. Рихтгофеном в 1877 году ${ }^{2}$. Обычно выделяют два направления Великого шелкового пути, условно называемых «северным» и «южным». Южное направление через Бактрию и Парфию достигало восточного побережья Средиземного моря, северное через Фергану и Хорезм выходило к ЮжноУральскому и Волго-Донскому регионам [11, с. 369-371]. Исследователи чаще обращались к изучению южного направления. Что касается северного направления, то остается ряд вопросов, требующих более обстоятельного их изучения, в частности, причин, приведших к началу функционирования этого направления, и определения времени этого события. Требует обсуждения и вопрос об информативности археологического материала при реконструкции этого торгового пути.

Определенные представления о времени начала сообщений по северному ответвлению Великого шелкового пути можно получить из сведений античных авторов. Следует обратить внимание на тот факт, что вплоть до Клавдия Птолемея (около 100 - около 170 гг.) античная география и история не имели в своем распоряжении каких-либо сведений о территориях к востоку от Танаиса (Дона). Известный географ Страбон (64/63 г. до н. э. $23 / 24$ г. н. э.) ничего не знал о крупнейшей европейской реке Волге, Каспийское море он считал заливом Северного океана (Strabo, XI, 6. 1). Другой эрудит античности, автор известного труда «Естественная история» Гай Плиний (22/24 - 79 гг. н. э.) практически повторяет то, что было сказано о Каспийском море
Страбоном, только океан, откуда берет свое начало это море, он именует Скифским (Plin. $\mathrm{NH}, \mathrm{VI}, 36)$.

Кардинальной новизной относительно рассматриваемого района отличаются сведения Птолемея, приведенные в его труде «Географическое руководство» по прошествии более ста лет после Страбона. Птолемей впервые упоминает о Волге, называя ее Ра. Он указывает точное расстояние между наибольшим сближением Ра (Волги) и Танаиса (Дона) (Ptol., V, 8, 13). У Птолемея это расстояние дано в градусах, если их перевести в меры длины, то в зависимости от того, какая мера им использовалась (эратосфеновский, обычный или царский стадий), это расстояние будет равняться от 64,5 до 87 км. Оно соответствует расстоянию от Волги до Дона на широте Волгограда и в зависимости от точки измерения колеблется в пределах 60-80 км. Кроме Волги, Птолемей на территории Северного Прикаспия называет другие реки, в частности Урал (Даикс), упоминает некоторые более мелкие реки. Он приводит названия ряда населенных пунктов на Дону и множества народов, обитавших на территории этого региона. Резонно возникает вопрос: из каких источников Птолемей получал столь точную информацию о районе, удаленном на несколько тысяч километров от Александрии Египетской, в предместье которой он жил и трудился? Такими информаторами могли быть только купцы, в древности они во многих случаях были первопроходцами, прокладывавшими пути в малоизвестные страны. Для купцов, по их же сведениям, составлялись «подорожники», своеобразные путеводители с указанием географических объектов, населенных пунктов, народов, проживающих в тех или иных местах. 
Птолемей, скорее всего, в описании Северного Прикаспия и пользовался таким «подорожником» [6, с. 200-203]. В Александрию тогда стекалась со всех концов света самая разнообразная информация. Во II в. н. э. Александрия была крупным торговым городом, связанным морскими путями с другими центрами Средиземноморья, многими странами Востока: Персией, Сирией, Индией. Кроме того, в то время Александрия являлась центром научной мысли античного мира. В ней находилась самая крупная библиотека, еще в I в. до н. э. в ней насчитывалось около 700 тыс. папирусных свитков, содержащих сведения по самым разнообразным отраслям знаний. Таким образом, информация о Поволжье и Северном Прикаспии в античной литературе появилась в период, определяемый датами жизни и деятельности Гая Плиния и Клавдия Птолемея: это примерно время между 70-ми гг. I в. н. э. и серединой II в. нашей эры.

О причинах отсутствия такой информации в предшествующее время говорил Страбон. Размышляя об истоках Танаиса, он отмечал, что реальных сведений о них у его современников практически нет. Причиной этому Страбон считал кочевников, отличавшихся многочисленностью и могуществом, которые «преградили доступ во все удобопроходимые места страны и в судоходные части реки» (Strabo, XI, 2, 2). Из сочинения Страбона, как мне представляется, можно определить, кем были эти кочевники. Перечисляя кочевнические группировки, обитавшие между Меотидой и Каспийским морем, он называет аорсов, подразделяя их на аорсов, живущих «по течению» Танаиса», и более многочисленных верхних аорсов, которые владели «большей частью побережья Каспийского моря» (Strabo, XI, 5, 8). Эти кочевнические объединения должны были занимать территорию, включающую правобережье Дона и Нижнее Поволжье, поскольку южнее их находились владения сираков, а между Доном и Днепром Страбон помещал роксоланов. Есть определенные основания отождествлять эти аорские группировки с археологическими памятниками заключительного этапа раннесарматской культуры (II-І вв. до н. э.) [23, S. 265).

Что же могло произойти за время между написанием трудов Плиния и Птолемея, что позволило получить столь обширную информацию об этом регионе, дошедшую до Египта? Из письменных источников известно, что в I в. н. э. на юге Восточной Европы появляется новое племенное объединение - аланы. Среди исследователей споры идут в основном об уточнении этой даты в пределах указанного века. Некоторые авторы полагают, что аланы были известны здесь уже в 35 г., другие относят это событие ко времени между 49 и 65 годами [20, с. 15-23]. Иосиф Флавий, приурочивая свою информацию к 72 г., помещал аланов у Меотиды и Танаиса, собственно там, где ранее по Страбону обитали аорсы. Видимо, эти события послужили сдвигу ряда племенных объединений с восточных территорий на западные. По крайней мере Плиний помещает аорсов уже к северу от Истра (Дуная), в местах, прилегающих к побережью Понтийского (Черного) моря (Plin. NH, IV, 80).

Наиболее полные сведения об аланах содержатся у Аммиана Марцеллина, который называл их бывшими или древними массагетами (Amm. Marc., XXXI, 2, 12), таким образом указывая на прежнее место их обитания. В настоящее время у большинства авторов сложилось мнение о том, что начало истории аланов связано с событиями II в. до нашей эры. В конце III в. до н. э. к северу от Китая сложилось мощное объединение кочевников во главе с хунну, ранга «кочевой империи» $[1$, c. 76-126], которое успешно проводило военные акции как против Китая, так и других своих соседей. Для нашей темы важным является завоевание хунну владений своих западных соседей юэчжей, произошедшее в 177 г. до н. э., а вслед за этим присоединение и земель усуней и переселение последних на запад [3, c. 107-113]. Результатом этой военной акции хунну был уход большей части этих племенных группировок на территорию Средней Азии, что значительно усилило кочевнический контингент этого региона и в конечном счете привело к падению Греко-Бактрийского царства. Ко II в. до н. э., видимо, относится и оформление такого государственного образования, как Кангюй в среднем течении Сырдарьи, которое имело города, но значительную часть его населения составляли кочевники. Формирование аланского племенного объединения, видимо, происходило в рамках этого государ- 
ственного образования. Об этом свидетельствует, например, следующий факт. Северозападнее Кангюя, на расстоянии 800 км от него, располагалось владение кочевников Яньцай. Во второй половине II в. до н. э. оно было независимым и обладало войском большим, чем у Кангюя [3, с. 100]. В «Хоу-Хань Шу» («История младшего Дома Хань», автор Фань Е), где события излагаются с 25 по 200 г., сообщается, что «владение Яньцай переименовалось в Аланья; состоит в зависимости от Кангюя» [2, с. 229]. Это может свидетельствовать о завоевании Яньцай аланами в русле политики, проводимой Кангюем [17, с. 205]. Владение Яньцай обычно отождествляется исследователями с аорсами античных источников [5, с. 61-66; 9, с. 20-21]. Китайские источники обозначали только восточные границы Яньцай, они могут совпадать с побережьем Аральского моря [3, с. 100] или северным побережьем Каспийского моря [9, с. 20]. Если исходить из тезиса отождествления Яньцай с аорсами, то западной его границей должен являться Танаис (Дон), у которого Страбон размещал аорсов.

Вся эта территория в связи с переименованием Яньцай в Аланию стала подвластна аланам. Это событие, судя по античным источникам, могло произойти в І в. н. э., возможно, в первой его половине. Они же говорят об огромной территории, контролируемой аланами, которая простиралась от Танаиса до реки индов Ганга (Amm. Marc., XXXI, 2, 13). Таким образом, можно утверждать, что аланы, являясь продуктом среднеазиатских этногенетических процессов, способствовали установлению разнообразных контактов между юго-восточными районами Европы и Средней Азии, устранив прежних владык аорсов, которые по каким-то причинам препятствовали налаживанию контактов между этими регионами. Правда, Страбон отмечал, что аорсы вели караванную торговлю индийскими и вавилонскими товарами, но этот торговый путь, судя по контексту его сочинения, проходил через Кавказ (Strabo, XI, V, 8). Отсутствие экономических связей через Северный Прикаспий во времена аорсов связано, видимо, с каким-то политическим конфликтом, что может следовать из фразы того же Страбона о том, что аорсы являлись «изгнанниками пле- мен, живущих выше» (Strabo, XI, V, 8). C переходом под контроль аланов бывшей территории Яньцай по прошествии какого-то времени, видимо, начинают налаживаться торговые контакты среднеазиатских районов через Нижнее Поволжье и Дон с Северным Причерноморьем, таким образом подключив эти территории к Великому шелковому пути. Только после этих событий подробная информация о Поволжье и Северном Прикаспии могла попасть на страницы географического сочинения Клавдия Птолемея.

Информация о произошедших этнических изменениях, полученная при анализе письменных источников, в определенной мере подтверждается и данными археологии. Происходят существенные изменения в погребальном обряде и материальной культуре, это нашло отражение в смене культур: на смену раннесарматской приходит среднесарматская культура. На Дону и в Поволжье появляются погребальные памятники, принадлежащие кочевой элите, типа Хохлач, Садовый, Дачи на Дону; Косика, Жутово в Нижнем Поволжье; Соколова могила, Пороги в Северном Причерноморье, не имеющие аналогов в предшествующей культуре. В них и других памятниках аналогичного типа обнаружены высокохудожественные вещи: богато оформленное оружие, конская упряжь, детали одежды, предметы, являющиеся символами власти. Многие из них выполнены в так называемом полихромном зверином стиле и обнаруживают близкие аналогии в известных погребальных комплексах ТиляТепе в Северном Афганистане. Исследователь этих комплексов В.И. Сарианиди отмечал, что большинство ювелирных изделий, найденных в них, были изготовлены местными бактрийскими мастерами, в связи с чем он считал возможным выделить «...бактрийский центр златоделия как наиболее вероятный источник, откуда ювелирные изделия широко распространялись по огромной территории от Урала до Днепра» [15, с. 82]. Эти памятники, видимо, в большей мере свидетельствуют не о торговых связях, а о том, откуда пришло новое кочевое сообщество, установившее свое господство в юго-восточных степях Европы.

На подтверждение наличия торговых связей юго-восточных районов Европы с центрально-азиатскими территориями могут пре- 
тендовать такие категории находок, как металлические китайские зеркала, которых только в доно-волго-уральских степях выявлено более десятка [4; 10, с. 23-27], шелковые ткани [7, с. 132-135; 16, с. 49], шкатулки китайского производства $[13 ; 22]$.

Ранее высказывалось мнение, что начало функционирования северного ответвления Великого шелкового пути относится к II-I вв. до нашей эры [12, с. 244; 14, с. 68, 69]. Е.И. Лубо-Лесниченко в своих выводах о датировке китайских зеркал, обнаруженных в сарматских погребениях, опирался на датировки аналогичных зеркал в самом Китае и переносил их на сарматские погребальные комплексы. Ю.А. Прокопенко следовал за выводами Е.И. Лубо-Лесниченко [19, с. 388-391]. Изучение погребальных комплексов сарматского времени с китайскими зеркалами показало, что ни один из них не может датироваться ранее рубежа нашей эры. Обычно в качестве примера ранней находки китайского зеркала, датируемого I в. до н. э., приводилось зеркало, обнаруженное с другими вещами в разрушенном погребении у хут. Виноградного Ростовской области. Авторы, опубликовавшие эту находку, приводили широкую ее дату - I в. до н. э. - І в. н. э., но все же, основываясь на дате самого зеркала и сопровождающих вещей, предпочтение отдавали I в. до нашей эры [8, с. 267]. Однако эта более узкая дата вызывает сомнение. Во-первых, неясно, происходят ли все находки, и зеркало в том числе, из одного или из разных комплексов. Как сообщают авторы, они были случайно найдены на глубине 1,8 м от современной поверхности (?). Из статьи даже неясно, была ли эта находка обнаружена в кургане или вне его. Но даже если это был единый комплекс, кем-то разрушенный, то датировка его более поздняя, чем та, к которой склонялись авторы публикации. Китайское зеркало не следует брать в расчет при определении общей даты находки, поскольку в юго-восточные степи они попадают в более позднее время, нежели то, которым они датируются на территории Китая. О причинах такой временной диспропорции распространения этих зеркал в разных регионах мы поговорим несколько ниже. В.М. Косяненко и В.Е. Максименко в определении времени находки у хут. Виноградного исходи- ли из старой датировки среднесарматской культуры. Кстати, металлическая кружка типа «Идрия», обнаруженная вместе с другими вещами, не обязательно должна датироваться временем исключительно до рубежа эр, аналогичные находки кружек происходят из Помпей, что свидетельствует об их существовании и в I в. нашей эры [18, с. 199, 200].

А.В. Симоненко, проанализировав условия находок китайских зеркал в Северном Причерноморье, пришел к выводу, что они встречаются в сарматских комплексах этого района, а также на Дону и в Поволжье в гораздо более позднее время, чем в Китае. Большинство их в памятниках юго-востока Европы, по его мнению, датируется временем конца I - первой половиной II в. нашей эры. Таким образом, разница в изготовлении этих зеркал в Китае и нахождении их в сарматских погребениях составляет 100-150 лет. Считать находки этих зеркал в Сарматии результатом торгового обмена можно было только при допущении, что купцы торговали китайским раритетом, что вряд ли соответствовало действительности. А.В. Симоненко приходит к выводу о том, что китайские зеркала попадают в степи юго-востока Европы из Средней Азии вместе с передвижением сюда кочевников, скорее всего, аланов [16, с. 46, 47].

Есть предположение, что причиной такой ситуации в передвижении китайских зеркал, а возможно, и других вещей от собственно Китая до Восточной Европы были события внешнего характера. Само начало формирования Великого шелкового пути связано с политическими событиями, характеризовавшимися противостоянием Китая и северных кочевников, под которыми понималось хуннское кочевое объединение. В поисках союзников в этой борьбе Китай обращается к тем народам Средней Азии, которые ранее обитали у западных границ Китая и в результате агрессивной политики хунну были вынуждены уйти в более безопасные восточные земли. Достаточно известна история с дипломатической миссией Чжан Цяня, посланного китайским правительством к этим народам с целью склонить их к союзу с Китаем в борьбе против хунну. Такой союз Китаю удалось заключить с усунями. Укрепляя союзнические отношения, Китай отправляет посольства, 
сопровождаемые караванами с подарками усуньскому предводителю, начиная от бамбуковых посохов и заканчивая китайскими принцессами. По данным Сыма Цяня, в год отправлялось до десяти таких посольств, зачастую состоящих из нескольких сотен человек [2, с. 158]. Таким образом, территория, контролируемая усунями, стала наполняться вещами китайского производства, но навряд ли они в массовом порядке распространялись за пределами, контролируемыми усунями. Это объясняется тем, что территории, располагавшиеся к северо-востоку от них, входили в состав владений государственного образования Кангюй, находившегося во враждебных отношениях с усунями и в союзнических с хунну. С Кангюем Китай долгое время не имел каких-либо отношений, это положение начинает меняться только к концу I в. до нашей эры [3, c. 308]. Напряженная политическая ситуация в этом районе не способствовала осуществлению каких-либо активных торговых акций и продвижению китайских товаров далее на запад. Ситуация коренным образом меняется только в I в. н. э. с выходом на политическую арену аланов.

Таким образом, находки вещей, связываемые с китайским производством, в сарматских погребениях первых веков нашей эры Волго-Донского региона и Северного Причерноморья необязательно связаны с торговыми операциями. Возможно, не все, но многие из них были принесены из Средней Азии новым племенным объединением, возглавляемым аланами.

Птолемей, выложив новую информацию о географии и народонаселении Поволжья и Северного Прикаспия, ничего не говорил о торговых путях, проходивших через эти районы. Он описал дорогу, идущую от Бактрии в страну серов (Китая) [11, с. 366]. Б.Я. Ставиский отмечал, что первое документальное (письменное) подтверждение существования торгового пути из Средней Азии через Поволжье относится только к раннему Средневековью [21, с. 18].

Подводя итог, следует отметить, что единственной информацией, служащей обоснованием наличия торгового пути, идущего через районы Средней Азии в Поволжье, на Дон и далее на запад, является «Географичес- кое руководство» Клавдия Птолемея, который, по общему мнению современных исследователей, должен был пользоваться подорожными записями (итинерариями) купцов и путешественников. Вряд ли существовали какиелибо другие источники. Появление в Поволжье, на Дону и Северном Причерноморье с I в. н. э. вещей, связанных своим происхождением с Китаем, как и ювелирных изделий, выполненных в полихромном зверином стиле, не следует трактовать как непременное свидетельство торговли по обозначенному пути. Какая-то их часть попала в юго-восточные европейские степи в результате отмечавшихся выше миграционных процессов, другая могла попасть сюда и в результате торговых операций. Эта проблема будет решаться с накоплением нового, преимущественно археологического материала и его объективным культурно-историческим анализом.

\section{ПРИМЕЧАНИЯ}

${ }^{1}$ Статья выполнена в рамках Государственного задания Министерства образования и науки РФ, проект № 33.2830.2017/4.6 «Юг России в эпоху раннего железного века: диалог культур Восток Запад».

2 Ф. Рихтгофен использовал термин Seidenstraße, дословно в переводе с немецкого «шелковая улица или дорога».

\section{СПИСОК СОКРАЩЕНИЙ}

ВДИ - Вестник древней истории.

ВолГУ - Волгоградский государственный университет.

НАВ - Нижневолжский археологический вестник (Волгоград).

РА - Российская археология.

СА - Советская археология.

СГУ - Саратовский государственный университет.

СПбГУ - Санкт-Петербургский государственный университет.

\section{СПИСОК ЛИТЕРАТУРЫ}

1. Барфилд, Т. Опасная граница. Кочевые империи и Китай (221 г. до н. э. - 1757 г. н. э.) / Т. Барфилд. - СПб. : Факультет филологии и искусств СПбГУ, 2009. -488 c. 
2. Бичурин, Н. Я. Собрание сведений о народах, обитавших в Средней Азии в древние времена / Н. Я. Бичурин. - Л. : Академия наук СССР, 1950. T. II. $-311 \mathrm{c}$.

3. Боровкова, Л. А. Царства «западного края» во II-І веках до н. э. (Восточный Туркестан и Средняя Азия по сведениям из «Ши цзи» и «Хань шу» / Л. А. Боровкова. - М. : Институт востоковедения PAH, 2001. $-368 \mathrm{c}$.

4. Гугуев, В. К. Ханьские зеркала и подражания им на территории юга Восточной Европы / В. К. Гугуев, М. Ю. Трейстер // РА. - 1995. - № 3.C. 143-164.

5. Гутнов, Ф. Х. Ранние аланы. Проблемы этносоциальной истории / Ф. Х. Гутнов. - Владикавказ : ИР, 2001.-256 с.

6. Ельницкий, Л. А. Знания древних о Северных странах / Л. А. Ельницкий. - М. : Географгиз, 1961. $-224 \mathrm{c}$.

7. Ковпаненко, Г. Т. Сарматское погребение І в. н. э. на Южном Буге / Г. Т. Ковпаненко. - Киев : Наукова думка, 1986. - $151 \mathrm{c}$.

8. Косяненко, В. М. Комплекс вещей из сарматского погребения у хутора Виноградного на Нижнем Дону / В. М. Косяненко, В. Е. Максименко // CA. - 1989. - № 1. - С. 264-267.

9. Кузнецов, В. А. История алан / В. А. Кузнецов. - Владикавказ : ИР, 1992. - 392 с.

10. Ли, Джи Ын. Китайский импорт в памятниках юга России (І в. до н. э. - III в. н. э.) : дис. ... канд. ист. наук: 07.00.06 / Ли Джи Ын. - Ставрополь, 2010. - $33 \mathrm{c}$.

11. Лубо-Лесниченко, Е. И. Великий шелковый путь / Е. И. Лубо-Лесниченко // Восточный Туркестан в древности и раннем средневековье. - М. : Наука, 1988. - С. 352-391.

12. Лубо-Лесниченко, Е. И. Китай на шелковом пути (Шелк и внешние связи древнего и раннесредневекового Китая) / Е. И. Лубо-Лесниченко. - М. : Восточная литература, 1994. - 326 с.

13. Мордвинцева, В. И. Погребение с остатками китайской лаковой шкатулки из могильника Октябрьский V / В. И. Мордвинцева, Е. П. Мысков // НАВ. - 2007. - Вып. 7. - С. 314-318.

14. Прокопенко, Ю. А. История северокавказских торговых путей IV в. до н. э. - XI в. н. э. / Ю. А. Прокопенко. - Ставрополь : Изд-во Ставроп. гос. ун-та, 1999. - 319 с.

15. Сарианиди, В. И. Бактрийский центр златоделия / В. И. Сарианиди // СА. - 1987. - № 1. - С. 72-90.

16. Симоненко, А. В. Китайские и ценральноазиатские элементы в сарматской культуре Северного Причерноморья / А. В. Симоненко // НАВ. 2003. - Вып. 6. - С. 45-65.

17. Скрипкин, А. С. Азиатская Сарматия. Проблемы хронологии и ее исторический аспект
/ А. С. Скрипкин. - Саратов : Изд-во СГУ, 1990. $300 \mathrm{c}$.

18. Скрипкин, А. С. К критике источников исследований, посвященных реконструкции торговых путей в скифо-сарматское время / А. С. Скрипкин // ВДИ. - 2003. - № 3. - С. 194-200.

19. Скрипкин, А. С. О времени включения Нижнего Поволжья в систему Великого шелкового пути / А. С. Скрипкин// НАВ. - 2002.-Вып. 5. - С. 388-393.

20. Скрипкин, А. С. О времени появления аланов в Восточной Европе и их происхождении (историографический очерк) / А. С. Скрипкин // Историко-археологический альманах. - Армавир ; М. : Армавирский краеведческий музей, 2001. Вып. 7. - С. 15-40.

21. Ставиский, Б. Я. Средняя Азия и античное Причерноморье. Проблема контактов, их периодизация и характер / Б. Я. Ставиский // Античная цивилизация и варварский мир : материалы III археол. семинара / отв. ред. Б. А. Раев. - Новочеркасск : Новочеркасский музей истории донского казачества : Изд-во КемГУ, 1992. - Ч. 1. - С. 14-18.

22. Puzdrovskij, A. Prunkbestattungen des 1. Jhs. n. Chr. in der Nekropole Ust'-Al'ma auf der Krim. Die Ausgrabungen des Jahres 1999/A. Puzdrovskij, Ju. Zajcev // Eurasia Antique. -2004. -Bd. 10. -S. 229-267.

23. Skvorcov, N. B. Eine sarmatische Adelsbestattung aus dem Wolgograder Wolgagebiet / N. B. Skvorcov, A. S. Skripkin // Eurasia Antiqua. 2006. - Bd. 12. - S. 251-268.

\section{REFERENCES}

1. Barfild T. Opasnaya granitsa. Kochevye imperii $i$ Kitay (221 g. do n. e. - 1757 g. n. e.) [Dangerous Border. Nomadic Empires and China (221 BC - 1757 AD)]. Saint Petersburg, Fakultet filologii $\mathrm{i}$ iskusstv SPbGU, 2009. $488 \mathrm{p}$.

2. Bichurin N.Ya. Sobranie svedeniy o narodakh, obitavshikh v Sredney Azii v drevnie vremena [Collection of Information about the Peoples Inhabiting Central Asia in Ancient Times]. Moscow, Leningrad, Akademiya nauk SSSR, 1950, vol. 2. 311 p.

3. Borovkova L.A. Tsarstva "zapadnogo kraya» vo II-Ivekakh do n. e. (Vostochnyy Turkestan i Srednyaya Aziya po svedeniyam iz «Shi tszi» $i$ «Khan shu» [The Kingdoms of the "Western Territory" in the 2nd - 1st Centuries BC (East Turkestan and Central Asia according to Information from the "Shi JI" and "Han Shu")]. Moscow, Institut vostokovedeniya RAN, 2001.308 p.

4. Guguev V.K., Treyster M.Yu. Khanskie zerkala i podrazhaniya im na territorii yuga Vostochnoy Evropy [Han Mirrors and Their Copies on the Territory of South Eastern Europe]. Rossiyskaya arkheologiya, 1995, no. 3, pp. 143-164. 
5. Gutnov F.Kh. Rannie alany. Problemy etnosotsialnoy istorii [The Early Alans. Problems of Ethno-Social History]. Vladikavkaz, IR Publ., 2001. 256 p.

6. Elnitskiy L.A. Znaniya drevnikh o Severnykh stranakh [The Knowledge of the Ancient People about the Nordic Countries]. Moscow, Gos. izd-vo geograficheskoy lit-ry, 1961. $116 \mathrm{p}$.

7. Kovpanenko G.T. Sarmatskoe pogrebenie I v. n. e. na Yuzhnom Buge [Sarmatian Burial Mound in the $1^{\text {st }}$ Century AD on the Southern Bug]. Kiev, Naukova dumka Publ., 1986. 151 p.

8. Kosyanenko V.M., Maksimenko V.E. Kompleks veshchey iz sarmatskogo pogrebeniya $\mathrm{u}$ khutora Vinogradnogo na Nizhnem Donu [Complex of Things from Sarmatian Burial Mound near the Vinogradny Village on the Lower Don]. Sovetskaya arkheologiya, 1989, no. 1, pp. 264-267.

9. Kuznetsov V.A. Istoriya alan [The History of Alans]. Vladikavkaz, IR Publ., 1992. 392 p.

10. Li Dzhi Yn. Kitayskiy import v pamyatnikakh yuga Rossii (Iv. do n. e. - III v. n. e.): dis. ... kand. ist. nauk [Chinese Import in the Monuments of the South of Russia ( $1^{\text {st }}$ Century BC $-3^{\text {rd }}$ Century AD). Cand. hist. sci. abs. diss.]. Stavropol, 2010. 33 p.

11. Lubo-Lesnichenko E.I. Velikiy shelkovyy put [The Great Silk Road]. Vostochnyy Turkestan v drevnosti i rannem srednevekovye [Eastern Turkestan in Antiquity and Early Middle Ages]. Moscow, Nauka Publ., 1988, pp. 352-391.

12. Lubo-Lesnichenko E.I. Kitay na shelkovom puti (Shelk $i$ vneshnie svyazi drevnego $i$ rannesrednevekovogo Kitaya) [China on Silk Road (Silk and Foreign Relations of Ancient and Early Medieval China)]. Moscow, Vostochnaya literatura Publ., 1994. 326 p.

13. Mordvintseva V.I., Myskov E.P. Pogrebenie s ostatkami kitayskoy lakovoy shkatulki iz mogilnika Oktyabrskiy V [Burial with the Remains of Chinese Lacquer Boxes from the Oktyabrsky-5 Burial Ground]. Lower Volga archaeological bulletin, 2007, iss. 7, pp. 314-318.

14. Prokopenko Yu.A. Istoriya severokavkazskikh torgovykh putey IV v. do n. e. $-X I$ v. n. e. [History of the North Caucasian Trade Routes in the $4^{\text {th }}$ Century BC $11^{\text {th }}$ Century AD]. Stavropol, Izd-vo Stavrop. gos. un-ta, 1999.319p

15. Sarianidi V.I. Baktriyskiy tsentr zlatodeliya [Bactrian Gold-Mining Center]. Sovetskaya arkheologiya, 1987, no. 1, pp. 72-90.
16. Simonenko A.V. Kitayskie i tsenralnoaziatskie elementy $\mathrm{v}$ sarmatskoy kulture Severnogo Prichernomorya [Chinese and Central Asian Elements in Sarmatian Culture of the North Pontic Region]. Lower Volga archaeological bulletin, 2003, iss. 6, pp. 45-65.

17. Skripkin A.S. Aziatskaya Sarmatiya. Problemy khronologii i ee istoricheskiy aspekt [Asian Sarmatia. Problems of Chronology and Its Historical Aspect]. Saratov, Izd-vo SGU, 1990. 300 p.

18. Skripkin A.S. K kritike istochnikov issledovaniy, posvyashchennykh rekonstruktsii torgovykh putey v skifo-sarmatskoe vremya [Critique of Research Sources Devoted to the Reconstruction of Trade Routes in the Scythian-Sarmatian time]. Vestnik drevney istorii, 2003, no. 3, pp. 194-200.

19. Skripkin A.S. O vremeni vklyucheniya Nizhnego Povolzhya $v$ sistemu Velikogo shelkovogo puti [About the Time of Inclusion of the Lower Volga Region in the System of the Great Silk Road]. Lower Volga archaeological bulletin, 2002, iss. 5, pp. 338-393.

20. Skripkin A.S. O vremeni poyavleniya alanov v Vostochnoy Evrope i ikh proiskhozhdenii (istoriograficheskiy ocherk) [About the Time of the Alans' Appearance in the Eastern Europe and Their Origin (Historiographic Essay)]. Istorikoarkheologicheskiy almanakh [Historical and Archaeological Almanac]. Armavir, Moscow, Armavirskiy kraevedcheskiy muzey, 2001, iss. 7. pp. 15-40.

21. Staviskiy B.Ya. Srednyaya Aziya i antichnoe Prichernomorye. Problema kontaktov, ikh periodizatsiya i kharakter [Central Asia and the Ancient North Pontic Region. The Problem of Contacts, Their Periodization and Character]. Raev B.A., ed. Antichnaya tsivilizatsiya $i$ varvarskiy mir: materialy III arkheol. seminara [Ancient Civilization and Barbarian World. Proceedings of the $3^{\text {rd }}$ Archaeological Seminar]. Novocherkassk, Novocherkasskiy muzey istorii donskogo kazachestva, KemGU Publ., 1992, part 1, pp. 14-18.

22. Puzdrovskij A., Zajcev Ju. Prunkbestattungen des 1. Jhs. n. Chr. in der Nekropole Ust'-Al'ma auf der Krim. Die Ausgrabungen des Jahres 1999. Eurasia Antique, 2004, Bd. 10, pp. 229-267.

23. Skvorcov N.B., Skripkin A.S. Eine sarmatische Adelsbestattung aus dem Wolgograder Wolgagebiet. Eurasia Antiqua, 2006, Bd. 12, pp. 251-268. 


\section{Information about the Author}

Anatoliy S. Skripkin, Doctor of Sciences (History), Professor, Department of Archaeology, Foreign History and Tourism, Volgograd State University, Prosp. Universitetsky, 100, 400062 Volgograd, Russian Federation, anatoly.skripkin@volsu.ru, adsi@volsu.ru, http://orcid.org/0000-0003-0141-5761.

\section{Информация об авторе}

Анатолий Степанович Скрипкин, доктор исторических наук, профессор кафедры археологии, зарубежной истории и туризма, Волгоградский государственный университет, просп. Университетский, 100, 400062 г. Волгоград, Российская Федерация, anatoly.skripkin@volsu.ru, adsi@volsu.ru, http://orcid.org/0000-0003-0141-5761. 